\title{
The Impact of Labour Relations on Innovative Output: An Exploration of Firm-level Data in the Netherlands
}

\author{
Haibo ZHOU \\ Erasmus School of Economics, Erasmus \\ University Rotterdam, \\ Rotterdam, The Netherlands \\ hzhou@few.eur.nl
}

\author{
Alfred KLEINKNECHT \\ Dept. Economics of Innovation, Delft \\ University of Technology \\ Delft, The Netherlands \\ A.H.Kleinknecht@tudelft.nl
}

\author{
Ronald DEKKER \\ Dept. Economics of Innovation, Delft \\ University of Technology \\ Delft, The Netherlands \\ Ronald.Dekker@tudelft.nl
}

\begin{abstract}
A growing literature on determinants of innovative performance focuses on factors such as market structure, firm size, (regional and international) knowledge spillovers, $R \& D$ collaboration, conditions for appropriation of innovation benefits, and others. This paper contributes to an aspect that is still sparsely explored: The impact of labour relations and Human Resource Management (HRM) practices on a firm's innovative behaviour. Our empirical findings identify that active HRM policies, including job rotation, performance pay, and high qualification levels of personnel contribute positively to innovative performance.
\end{abstract}

\section{THE PROBLEM}

Literature on the impact of labour relations on innovation suggests that active Human Resource Management (HRM) policies might be rewarding for a firm's innovation and productivity growth (e.g. Verburg 2005; Kleinknecht et al. 2006). Micro-econometric evidence on the impact of HRM policies on innovation, however, is still sparse. In this paper we make use of firm-level data that have been collected by the Organisation for Strategic Labour Market Research (OSA) in the Netherlands. OSA is sampling all organizations that employ personnel with a minimum of five employees. For our analysis we use data from the 2001 survey, which contains information on the period 1998-2000 for 1482 commercial establishments covering all manufacturing and commercial service sectors.

In the Netherlands, there is a fairly wide spectrum of labour management practices. One end of the spectrum covers typically 'Rhineland' enterprises with internal labour markets that offer employees good wages, fair protection against dismissal, and long-term commitments. The other end of the spectrum includes enterprises that follow Anglo-Saxon practices; the latter employ lots of labour on shorter-term employment contracts, labour hired temporarily from manpower agencies or 'free lance' workers (i.e. self employed small entrepreneurs that have no personnel).

There is one strand of literature that suggests that 'Rhineland' practices are more conducive to innovation and labour productivity growth (e.g. Buchele \& Christiansen 1999 for evidence from macro data; or Kleinknecht et al. 2006 for evidence from firm-level data). The rationale is that a longer-term commitment between the firm and its employees may function as an investment into 'social capital'; i.e. into loyalty and commitment of workers. The latter will diminish the probability of opportunistic behaviour such as the stealing of a firm's properties or leaking to competitors of crucial trade secrets or new technological knowledge. Moreover, it has been argued that, in a Schumpeter II innovation model, the quality of a firm's products and/or its efficient process performance crucially depends on the long-run historical accumulation of technological knowledge. Much of this knowledge is 'tacit'. Other than publicly documented and codified knowledge, tacit knowledge is defined as 'un-codified', ill-documented and idiosyncratic; tacit knowledge is based on personal experience (Polanyi 1966). The continuous and long-run accumulation of knowledge and of 'tacit' knowledge in particular, is favoured by continuity in personnel, i.e. by keeping people in the firm over longer periods. A longer stay with the same employer will also enhance a firm's readiness to invest in education and training.

Against this one can argue that 'Anglo-Saxon' practices might be favourable to a firm's innovation potential. With higher rates of labour-turnover, firms can increase the inflow of fresh people with new ideas, skills and networks. Moreover, less productive people can be more easily replaced by more productive ones, and the threat of firing might increase the productivity of employees. Easier hiring and firing could also help to keep wages low and allow for a more flexible reallocation of labour. Ichniowski and Shaw (1995) argue that (long) tenured employees may be conservative to out-dated products and processes. Innovation may therefore be difficult to implement. From this viewpoint, one could argue that some flexibility of labour is needed for innovation, especially for radical innovation.

\section{HYPOTHESES TO BE TESTED}

For our test of the impact of HRM practices on innovation, the OSA database offers a wide range of interesting indicators. As a dependent variable, we use the log of new product sales per employee in year 2000. In the OSA survey, firms are asked to subdivide their present product range into three types of product:

(1) Products that remained largely unchanged during the past two years;

(2) Products that were incrementally improved during the past two years; and

(3) Products that were radically changed or introduced entirely new during the past two years. 
Subsequently, firms are asked to report the share of these three types of product in their last year's total sales. In this paper we add up categories (2) and (3), i.e. incremental and radical innovations. One should note that the new product sales according to definition (2) and (3) need to be novel in that they include new technological knowledge or, at least, they should be based on novel (and creative) combinations of existing technological knowledge. The products under (2) and (3) can include products that are new to the firm (already known in the market) or products that are first in the market.

In our model that explains a firm's score on the log of 'new product sales per employee', we use a number of labour relations indicators as independent variables, besides other control variables. Our independent variables are detailed in Table III/1.

The HRM variables include indicators for both HRM outcomes and specific HRM policies. HRM outcomes include proxies for external labour flexibility (percentages of temporary workers), internal labour flexibility and the educational level of the workforce (percentage of workers with higher education). Furthermore we include two dummy variables, for job rotation and for performance pay. In principle, we expect the six HRM variables in the table to have a positive impact on new product sales, although the impact of temporary contracts might be ambiguous. On the one hand, shorter term commitments might undermine loyalty of workers and the continuity in knowledge accumulation. On the other hand, lots of highly educated people are, notably in their first job, hired on a temporary basis, often with a perspective of tenure. Moreover, specialist technical and commercial consultants can often be hired on a temporary basis. We make a distinction between short-term and long-term hiring, the division line being 9 months of contract. We would expect that notably when hired on a longer-run basis, such people may positively add to innovative output, even if hired only temporarily.

Our three most important control variables include: (1) A firm's R\&D intensity. Of course, if there is more $R \& D$ input, we expect there to be more output in terms of new product introductions. (2) Firm size. Small firms have advantages such as little bureaucracy, short communication lines, or dedicated management by the owner/manager. The literature also reports, however, typical shortcomings of the innovation process in small firms: A strong dependence on the owner as a key person; or a chronic lack of financial and other resources (e.g. technological knowledge; see Tidd et al. 2006). Larger firms also have the advantage that they can maintain larger portfolios of risky projects, thus diminishing their innovative risks by means of diversification. In smaller firms, the innovation process often is a zero/one decision: failure of a single project can mean the end of the firm, while success can mean exceptional growth. (3) Industry average new product sales: A firm's score on the dependent variable (log of new product sales per employee) crucially depends on the typical length of the product life cycle in a firm's sector of principal activity. Obvi- ously, sectors with typically short product life cycles (such as food or fashion) will have higher rates of new product introductions (and higher sales of new products) than sectors with long life cycles such as aircraft production. The dependent variable can therefore not be compared across sectors, unless we correct for life cycle differences. As life cycle data are not easily collected in postal surveys, we use, as a substitute, the log of average new products sales in a firm's sector of principal activity. Besides correcting for typical differences in product life cycles between sectors, this variable can also pick up other unobserved specifics of sector (indeed, inclusion of this variables makes sector dummies insignificant). Besides, we also include dummies for a firm's focus on information and communication technologies which might enhance a firm's innovation activities.

\section{RESULTS}

Our regression estimates are summarized in Table III/1. The reader should note that we do not explain whether a firm will innovate or not. We explain the log of sales (per employee) achieved by firms that have such sales. In other words, our interpretation is strictly confined to the group of innovating firms among the respondents to the OSA survey. We used a Tobit procedure (see: Maddala, 1985) to correct for the specific non-normality of the distribution of our dependent variable. This nonnormality stems from the relatively large number of firms that have zero new product sales. These are the censored observations in the Tobit output.

It is no surprise that $R \& D$ intensity has a positive impact on innovative output. Processes related to a firm's innovativeness such as the introduction of new logistic or ICT processes or the firm using the Internet are, as expected, positively related to new products sales. And of course, an individual firm's new sales performance depends on the average standards of its sector of principal activity. Inclusion of the latter variable implies, by the way, that our model explains a (positive or negative) deviation of an individual firm's new products sales from its sector average. As to firm size, we have to conclude that the typical advantages or disadvantages of a firm being small or big seem to cancel out each other: there is no difference in new products sales across size classes.

Further, we can conclude that most of our human resource management variables behave as expected. High shares of highly educated personnel enhance new product sales, although this is only significant at a $10 \%$ level. The same holds for job rotation. Moreover, performance pay (including profit sharing arrangements) is positively related to innovative output. This reflects the practice that firms give financial incentives to qualified people in order to keep them in the firm, rather than letting them leave and take along their (tacit) knowledge to competitors. To our surprise, however, a high rate of internal ('functional') flexibility does not seem to contribute to new product sales. In related estimates, we found that high internal flexibility did contribute to 
overall sales growth, notably among innovating firms (Kleinknecht et al. 2006). As to people on temporary contract, it is interesting to note that higher shares of people with longer contracts ( $>9$ months) have a weakly significant positive impact on new product sales, while high shares of people on shorter contracts do not contribute significantly. In an alternative version of our estimate (not documented here) we found that high rates of temporary contracts (without distinction by contract length) had a significant positive impact on new product sales. This gives some support to the above-quoted argument by Ichniowski and Shaw (1995).

In conclusion, we find strong indications that active HRM policies, including job rotation, performance pay, and high qualification levels of personnel do contribute positively to innovative sales, while the impact of flexibility remains ambiguous. We should add that the model estimated in Table III/1 is fairly robust to small model changes (e.g. replacing our size class dummies by a continuous variable). We also experimented with quadratic terms, finding only little evidence of non-linear relationships. An important qualification of our findings is the use of a survey in one year only. This does not allow handling time lags between our exogenous and endogenous variables. Future research should include panel data which will, however, lead to a substantial loss of observations.

\section{IMPLICATIONS}

While some of our findings are in favour of the view that 'Rhineland' practices may support innovative performance, the evidence is not clear-cut. On the one hand, we find that systems of job rotation and performance pay contribute positively to innovative output; on the other hand, and against our expectation, high rates of internal flexibility do not. Intuitively one would expect that innovative activities are related to high rates of people changing their function or department within the firm. It is therefore puzzling that we do not find a posi- tive coefficient for internal flexibility. Moreover, our estimates give indications that high shares of temporary employees seem to contribute positively to new product sales, while the same variable contributed negatively to the growth of labour productivity in recent a study using the same database (Kleinknecht et al. 2006). As a qualification, we should note that our model in table III/1 is estimated on one vintage of the OSA database only. Future research should exploit the panel character of the database.

Despite these qualifications, one should note that our model in table III/1 is fairly robust to changes in model specification. Moreover, variables such as a firm's R\&D intensity, the use of Internet or the implementation of new logistic processes have the expected signs. As expected, the average new product sales performance in a firm's sector of principal activity turns out to be a very important control variable.

\section{LITERATURE}

[1] Buchele, R. \& J. Christiansen (1999). Employment and productivity growth in Europe and North America: The impact of labour market institutions. International Review of Applied Economics, Vol. 13, p. 323.

[2] Kleinknecht, A., R.M. Oostendorp, M.P. Pradhan \& C. W. M. Naastepad (2006). Flexible labour, firm performance and the Dutch job creation miracle. International Review of Applied Economics, Vol. 20, No. 2, April, S. 171-187.

[3] Ichniowski,C.\& Shaw, K. (1995). Old dogs and new tricks; determinants of the adoption of productivityenhancing work practices. Brookings Papers: Microeconomics, pp. 1-55.

[4] Polanyi, M (1966). The tacit dimension. London: Routledge.

[5] Tidd, J. J. Bessant \& K. Pavitt (2006). Managing Innovation. Chichester: Wiley.

[6] Verburg, R. M. \& Den Hartog (2005). Human Resource Management for advanced technology. In: R.M. Verburg, J. R. Ortt, \& W. M. Dicke (Eds.). Managing Technology and Innovation. Oxon: Routledge, pp. 43-64.

Table III/1 Factors that influence a firm's sales of new products. Summary of Tobit regression estimates

\begin{tabular}{|c|c|c|}
\hline HRM variables: & Coefficients & t-values \\
\hline Share of workers on temporary contract* short-term contracts ( $<9$ months are more important); cross dummy & 0,072 & 1,36 \\
\hline $\begin{array}{l}\text { Share of workers on temporary contract*longer-term contracts ( }>9 \text { months are more important); cross } \\
\text { dummy }\end{array}$ & $0,093^{*}$ & $1,76^{*}$ \\
\hline Internal flexibility: Percentages of workers that changed their function and/or department within the firm & $-0,02$ & $-0,27$ \\
\hline Percentages of workers with university or higher professional education degrees & $0,041 *$ & $1,85^{*}$ \\
\hline Dummy: Firm has systems of performance pay (e.g. profit sharing arrangements) & $2,429 * *$ & $2,51 * *$ \\
\hline Dummy: Firm employs job rotation systems & $1,738^{(*)}$ & $1,64^{(*)}$ \\
\hline \multicolumn{3}{|l|}{ Control variables: } \\
\hline Dummy: Firm uses internet or will have internet access within two years & $6,396 * *$ & $3,19 * *$ \\
\hline Dummy: Organization introduced new logistic or ICT processes in the last 2 years & $3,876^{* *}$ & $3,21 * *$ \\
\hline Percentage share of turnover spent on Research \& Development & $0,308 * *$ & $3,42 * *$ \\
\hline Dummy: number of employees is between 21 and 99 & 0,786 & 0,67 \\
\hline Dummy: number of employees is between 100 and 499 & 0,506 & 0,40 \\
\hline Dummy: number of employees is 500 and larger & $-0,074$ & $-0,04$ \\
\hline Average of logs of new product sales per employee in a firm's sector of principal activity & $2,160 * *$ & $4,07 * *$ \\
\hline Constant term & $-21,990 * *$ & $-7,15^{* *}$ \\
\hline \multicolumn{3}{|c|}{$\begin{array}{l}{ }^{(*)} \text { Coefficient just fails to be significant at } 10 \% \text { level } \quad *=\text { significant at } 10 \% \text { level } \\
\text { No. of observations: } 335 \text { uncensored observations, } 565 \text { censored observations } \\
\text { LR chi2 }(13)=93.04 \quad\left(\operatorname{Pr}>\chi^{2}=0.0000\right)\end{array}$} \\
\hline
\end{tabular}


Log likelihood $=-1623.9698$

Pseudo $\mathrm{R}^{2}=0.0278$ 